\title{
Gyroid-Structured 3D ZnO Networks Made by Atomic Layer Deposition
}

\author{
Ellie Kim, Yana Vaynzof, Alessandro Sepe, Stefan Guldin, Maik Scherer, Pedro Cunha, \\ Stephan V. Roth, and Ullrich Steiner*
}

3D continuous $\mathrm{ZnO}$ morphologies with characteristic feature sizes on the $10 \mathrm{~nm}$ length scale are attractive for electronic device manufacture. However, their synthesis remains a challenge because of the low crystallization temperature of $\mathrm{ZnO}$. Here, we report a method for the robust and reliable synthesis of fully crystalline 3D mesoporous $\mathrm{ZnO}$ networks by means of atomic layer deposition (ALD) of ZnO into a self-assembled block copolymer template. By carefully optimizing the processing conditions we are able to synthesize several-micrometer-thick layers of mesoporous $\mathrm{ZnO}$ networks with a strut width of $30 \mathrm{~nm}$. Two 3D mesoporous morphologies are manufactured: a periodic gyroid structure and a random worm-like morphology. Exploiting the ALD property to conformally coat complex surfaces of high aspect ratio, the channel network of a 3D continuous channel network of a self-assembled block copolymer is replicated into $\mathrm{ZnO}$. X-ray photoemission spectroscopy and $\mathrm{x}$-ray diffraction measurements reveal that the chemical composition of the mesoporous structures is uniform and consists of wurtzite- $\mathrm{ZnO}$ throughout the film. Scanning electron microscopy reveals an average pore dimension of $30 \mathrm{~nm}$. The potential of this material for a hybrid photovoltaic application is demonstrated by the manufacture of a poly(3-hexylthiophene)/ $\mathrm{ZnO}$ solar cell.

are of technological interest in emerging areas of nanotechnology as they offer opportunities for applications that require a high surface area or hybrid materials.

Unlike other transition metal oxides, such as $\mathrm{TiO}_{2}$ and $\mathrm{SnO}_{2}$, and despite equally desirable properties, $\mathrm{ZnO}$ is very diffcult to process into well-defined morphologies on the sub-100 nm length scale. Instead of the well-defined 3D structures that are possible with other metal oxides, ${ }^{[3]}$ 1D $\mathrm{ZnO}$ morphologies can be produced via anisotropic growth to form nanorods, nanowires, nanocoils, and nanoforests. ${ }^{[4-6]}$ The difference from the other metal oxides lies in the rapid crystallization of $\mathrm{ZnO}$ from solution. In contrast to, for example, $\mathrm{TiO}_{2}$, which is amorphous during roomtemperature deposition and crystallizes only upon heating, $\mathrm{ZnO}$ crystallization sets in at room temperature. Therefore, attempts to mold $\mathrm{ZnO}$ into design structures using sol-gel or electrodeposition methods have been unsuccessful, because structure formation is governed by $\mathrm{ZnO}$ crystallization and not the mold. Reports

\section{Introduction}

$\mathrm{ZnO}$ is a direct semiconductor with a wide bandgap of $3.37 \mathrm{eV}$ with piezoelectric, photocatalytic, and gas-sensing properties. ${ }^{[1]}$ In its thin-film form, it is used as a transparent (semi)-conductive electrode for optoelctronic and solar cell applications. ${ }^{[2]}$ Three-dimensional, porous structures of $\mathrm{ZnO}$

Dr. E. Kim, Dr. Y. Vaynzof, Dr. A. Sepe, Dr. S. Guldin, ${ }^{[+]}$ Dr. M. Scherer, P. Cunha, Prof. U. Steiner

Cavendish Laboratory

Department of Physics

University of Cambridge

J. J. Thomson Avenue, Cambridge, CB3 OHE, UK

E-mail: u.steiner@phy.cam.ac.uk

Dr. S. V. Roth

HASYLAB at DESY

Notkestr. 85, 22607, Hamburg, Germany

[+]Present address: Supramolecular Nano-Materials and Interfaces, Laboratory, Department of Materials Science, Ecole Polytechnique Federale de Lausanne, 1015 Lausanne, Switzerland

DOI: $10.1002 / \mathrm{adfm} .201302238$ on porous $\mathrm{ZnO}$ structures using such methods showed the replication of pore sizes larger than $200 \mathrm{~nm}^{[7]}$ or poorly defined morphologies. ${ }^{[8,9]}$

In this work, the problems of rapid crystallization during deposition was circumvented by the use of atomic layer deposition (ALD) to replicate periodic and random 3D networks generated by the microphase separation of a block copolymer (BCP). This enables the fabrication of 3D continuous structures of $\mathrm{ZnO}$ with feature sizes below $50 \mathrm{~nm}$ and controllable layer thicknesses ranging from $200 \mathrm{~nm}$ to several microns.

BCPs self-assemble into well-defined morphologies with tunable feature sizes ranging between $10-100 \mathrm{~nm}$. The resulting morphologies are governed mainly by the molecular architecture of the BCP, with spherical, cylindrical and lamellar arrays being most commonly obtained in diblock copolymers. The more elusive double gyroid morphology is a particularly appealing candidate for the manufacture of 3D bicontinuous nanostructured templates. The double gyroid consists of two interwoven, periodic, continuous networks of the minority block surrounded by a matrix of the majority block. ${ }^{[10]}$ It provides a useful template for the replication of self-supporting $10 \mathrm{~nm}$ scaffolds into metals and metal oxides, which have been 
a

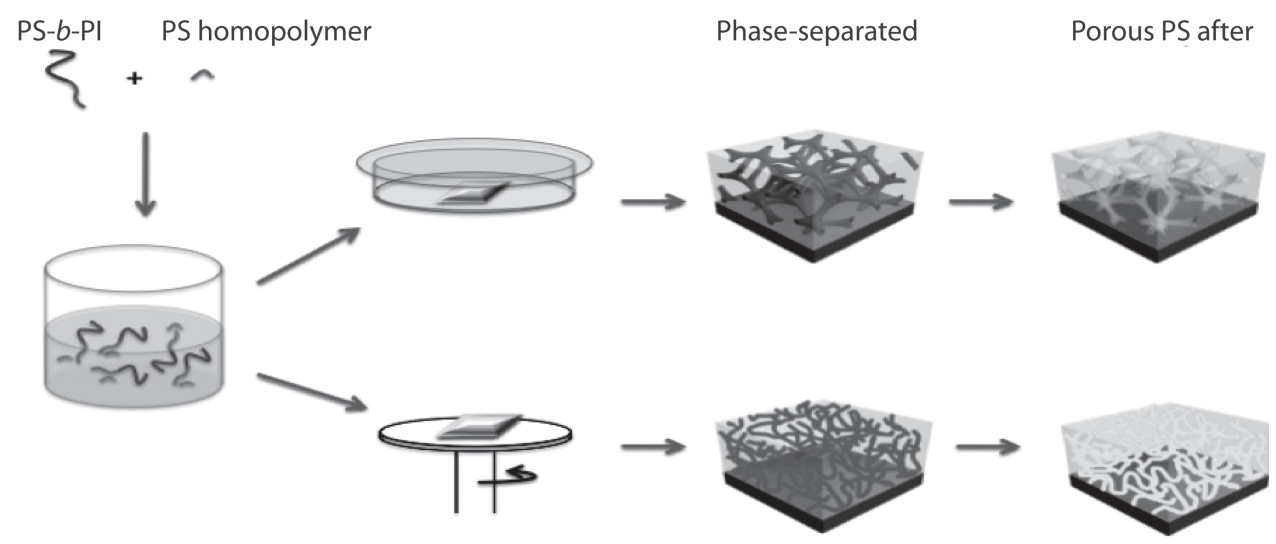

b

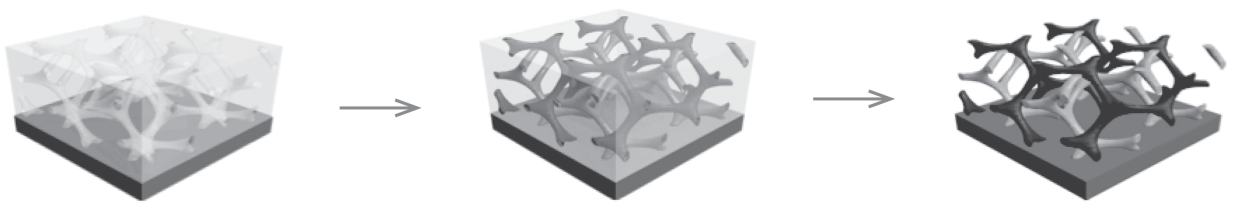

Figure 1. Schematic representation of the sample preparation procedure: a) a porous PS template is created by BCP phase separation followed by selective $\mathrm{PI}$ etching, and b) ALD replication of the polymer template by $\mathrm{ZnO}$.

employed in the manufacture of dye-sensitized solar cells, electrochromic devices, and supercapacitors.

While the self-assembly of BCPs into the gyroid phase is often challenging and slow, a faster and more robust use of BCP self-assembly employs off-equilibrium morphologies. Cylinder and gyroid-forming BCPs are often observed to form 3D interconnected bicontinuous worm-like morphologies when quenched off equilibrium. ${ }^{[11]}$ Although less periodic, the formation of worm-like structures in thin films with bicontinuous microphases is simpler and more robust compared to the equilibration into the gyroid morphology. These non-equilibrium structures are therefore good candidates for the scalable synthesis of functional nanomaterials.

BCP self-assembly has been used to pattern metal oxides either by the co-assembly of a precursor sol ${ }^{[12]}$ and as a sacrificial template for metal and metal-oxide electrodeposition ${ }^{3}$ and solution impregnation. ${ }^{[13]}$

ALD is a precise chemical vapor deposition (CVD) technique for the three-dimensional, conformal replication of a scaffold in a highly controlled manner. Successful 3D deposition requires, however, a careful optimization of processing parameterssuch as exposure time to the precursor gases, precursor partial pressure, and deposition temperature-all of which have to be adjusted to the aspect ratio and surface chemistry of the porous substrates. Several models and simulation methods have been suggested to describe conformal deposition onto very high aspect ratio (over 10 000) substrates, such as alumina membranes (AAO), nanotubes, or inverse opals. ${ }^{[14-16]}$ Wang et al. reported the deposition of $\mathrm{ZnO}$ onto a complex polymer structure of tubular shape. ${ }^{[17]}$ Despite this early work, the replication of BCP templates by ALD to yield a 3D metal oxide structure has remained a considerable challenge.
The purpose of this study is the demonstration of a method for the manufacture of 3D continuous mesoporous $\mathrm{ZnO}$ network structures by replicating a self-assembled polymer substrate using ALD, exploiting the advantages of both methodologies. Starting with a porous template obtained by BCP self-assembly followed by the selective etching of one of the polymer phases, ZnO was conformally deposited by ALD, replicating the complex 3D high aspect ratio gyroid internal surfaces by $\mathrm{ZnO}$. The use of this material in a solar cell is demonstrated.

\section{Results and Discussion}

\subsection{Mesoporous ZnO Preparation}

\subsubsection{Polymer Templates}

Figure 1 demonstrates the sample preparation procedure. Periodic gyroid and random worm-like structured films were fabricated from the same polymer solution, a mixture of a lamellae-forming polystyrene-polyisoprene (PS-PI) BCP and PS homopolymer. ${ }^{[18,19]}$ The ratio of the two polymers was finely adjusted to an overall PS volume fraction of $65 \%$, which is a requirement for the formation of the double gyroid phase.

The double gyroid morphology was obtained by carefully annealing the film into its narrowly defined phase equilibrium, which requires a slow solvent evaporation process. The worm-like structure is, on the other hand, readily obtained by quenching the film by spin-coating, which yields a morphology that is far from thermodynamic equilibrium.

Both template systems have distinct benefits. The gyroid morphology provides a highly ordered, periodic 3D structure. 

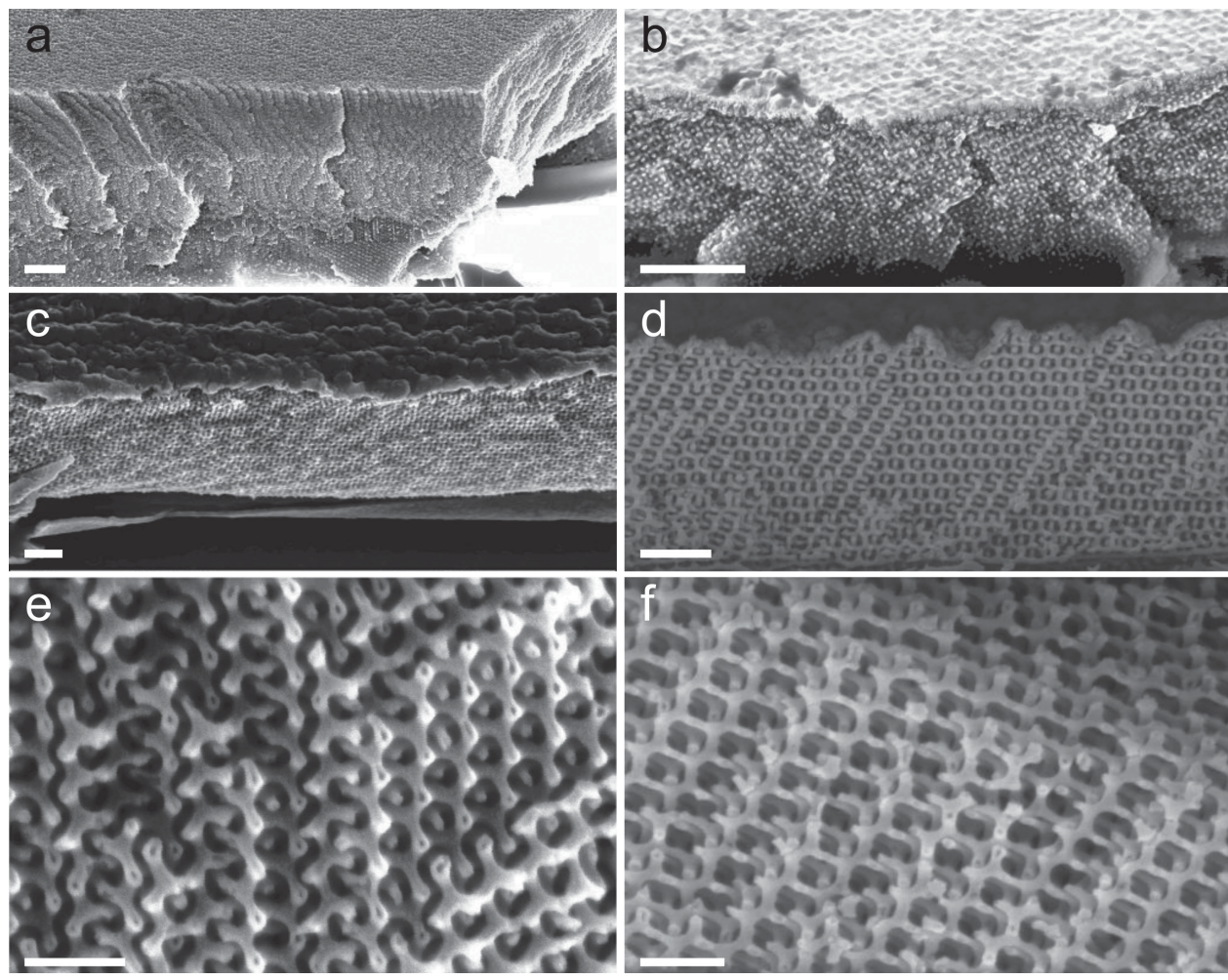

Figure 2. Side-view SEM images at a $45^{\circ}$ angle of gyroid replication into $\mathrm{ZnO}$ : a) gyroid polystyrene template, b) as-deposited $\mathrm{ZnO}$-PS hybrid, and c) $\mathrm{ZnO}$ gyroid after annealing at $550^{\circ} \mathrm{C}$. d,e,f) Different faces of the $\mathrm{ZnO}$ gyroid shown in (c). The scale bars correspond to $1 \mu \mathrm{m}$ for (a) and (b), $400 \mathrm{~nm}$ for (c) and (d), $200 \mathrm{~nm}$ for (e) and (f).

Its manufacture by drop-casting and slow solvent annealing remains, however, a challenge. The thickness of the polymer template can be roughly controlled by varying the concentration of the deposition solution, yielding values between 2 and $8 \mu \mathrm{m}$.

The worm-like morphology, on the other hand, is not as periodic as the gyroid. It nevertheless provides a well-defined bicontinuous porous morphology. (Figure 1) The processing conditions are easy and quick (ca. $15 \mathrm{~h}$ ) compared to those based on the gyroid templates (over 8 days) and the resulting films are of consistent smoothness and thickness. By varying the polymer solution concentration and the spin-coating conditions, controlled thickness between $200 \mathrm{~nm}$ and $3 \mu \mathrm{m}$ were obtained.

For both systems, upon complete evaporation of the solvent, the PI block was removed to provide a porous network of pores for the deposition of $\mathrm{ZnO}$. To this end, the polymer film was exposed to UV light $(254 \mathrm{~nm})$ and immersed in ethanol for up to $15 \mathrm{~h}$, resulting in a 3D porous polystyrene structure, as shown in Figure 2a and Figure 3a. ${ }^{[18,19]}$ The UV exposure not only breaks down the backbone of the PI, it also creates carboxylic groups on the PS. ${ }^{[20]}$ Thus, upon ethanol immersion, the PS surface is terminated by $\mathrm{OH}$ groups, which is an important requirement for the conformal ALD deposition of $\mathrm{ZnO}$.

\subsubsection{ALD Deposition of ZnO onto a Mesoporous PS Template}

The steps of the replication process in Figure $1 \mathrm{~b}$ are demonstrated in the scanning electron microscope (SEM) images of Figure $2 \mathrm{a}-\mathrm{c}$ and Figure $3 \mathrm{a}-\mathrm{c}$. $\mathrm{ZnO}$ was deposited via ALD using diethyl zinc (DEZ) and $\mathrm{H}_{2} \mathrm{O}$ precursors onto the template, followed by removal of the polymer. The $\mathrm{ZnO}$-polymer hybrid (before removal of the polymer) is shown in Figure $2 \mathrm{~b}$. The polymer template and the area where insufficient $\mathrm{ZnO}$ was deposited appear dark in the SEM images because of charging of the non-conductive PS template.

ALD deposition into polymer templates requires the careful selection of the deposition temperature. The ALD deposition window for $\mathrm{ZnO}$ is $80-150{ }^{\circ} \mathrm{C}$, delimited by the minimum precursor reaction temperature and the precursor desorption from the template walls. ${ }^{[21]}$ PS has a glass transition temperature of $100^{\circ} \mathrm{C}$. To test the softening temperature of the crosslinked self-assembled PS templates they were annealed for $24 \mathrm{~h}$ at temperatures up to $120^{\circ} \mathrm{C}$. The cross-linked polymer template was found to withstand up to $110^{\circ} \mathrm{C}$, above which deformation of morphology and collapse of the polymer structure was observed. In order to keep this method applicable for other different types of polymer templates, the default deposition temperature was kept at $80{ }^{\circ} \mathrm{C}$, the lowest possible of the conformal deposition window. The $100{ }^{\circ} \mathrm{C}$ deposition was later investigated to explore the deposition temperature dependence of crystallite size of deposited $\mathrm{ZnO}$, but the crystallite size did not differ from that of $80^{\circ} \mathrm{C}$ deposition (see below).

The diameter of the void channels running through the polymeric template was roughly $32 \mathrm{~nm}$ for gyroid, and 25-35 nm for the worm-like structure. Given that the growth rate of $\mathrm{ZnO}$ deposition is approximately $1.5-2.2 \AA$ cycle $^{-1},[7,22] 110$ cycles of $\mathrm{ZnO}$ were deposited in order to aim for a minimum of $16.5 \mathrm{~nm}$ 

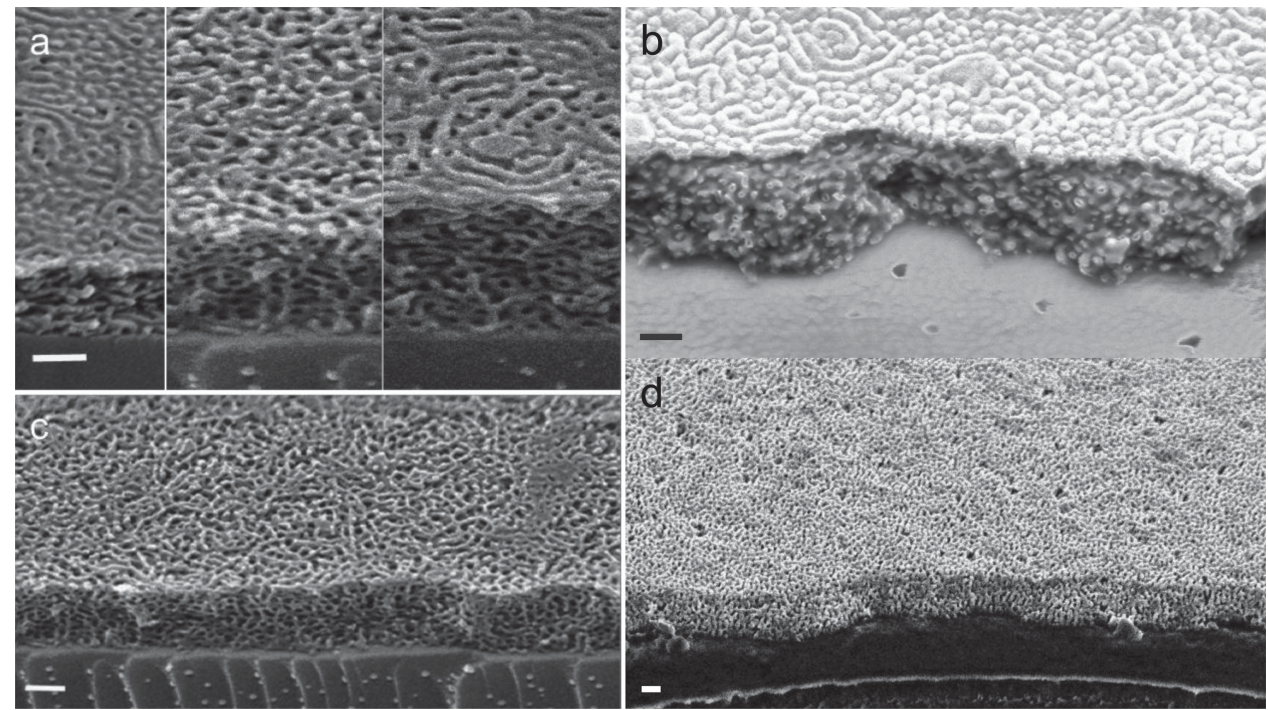

Figure 3. SEM of ZnO replication of the worm-like morphology: a,c) worm-like polystyrene template; b) as-deposited ZnO-PS hybrid, and; d) ZnO morphology after annealing at $400^{\circ} \mathrm{C}$ followed by ICP etching of the top compact layer. All scale bars correspond to $200 \mathrm{~nm}$.

deposition on the template surface, which under the assumption of conformal coating should completely fill the voided network. The thin solid layer of $20 \mathrm{~nm}$ that has formed on top of the porous film results from the surface-limited, conformal deposition, which can easily be removed using dry etching methods such as reactive ion etching (RIE) or inductive coupled plasma etching (ICP).

After removal of the PS matrix by heating the sample to $400{ }^{\circ} \mathrm{C}$ or by exposure to an oxygen plasma, freestanding $\mathrm{ZnO}$ networks are revealed. The replicated $\mathrm{ZnO}$ gyroid film is self-standing and highly periodic with a consistent channel diameter of approximately $30 \mathrm{~nm}$. Figure $2 \mathrm{~d}-\mathrm{f}$ shows other lattice faces of the gyroid $\mathrm{ZnO}$ structure imaged from different angles. The worm-like structure was similarly replicated using ALD, fabricating 3D bicontinuous ZnO replica with film thicknesses of $200 \mathrm{~nm}$ to $2 \mu \mathrm{m}$ (Figure 3a,c). The similar quality of the replicated networks in Figures 2 and 3 proves that the worm-like polymer template has a similar pore connectivity as the double gyroid. Both $\mathrm{ZnO}$ structures were annealed at temperatures between 400 and $550{ }^{\circ} \mathrm{C}$, demonstrating the stability of both network types in this temperature range. The stability of the $\mathrm{ZnO}$ mesomorphology at temperatures above the complete degradation of PS (between 300 and $400{ }^{\circ} \mathrm{C}$ ) mirrors the good structural integrity observed in other metal-oxide mesomorphologies..$^{[23]}$

The successful replication of the $\mathrm{ZnO}$ networks in Figures 2 and 3 required the careful optimization of ALD parameters. Two types of exposure methods were explored: continuous flow and stop-flow methods, as described by Karuturi et al. ${ }^{[15]}$ The exposure times required for successful replication were comparable to those reported for high-aspect-ratio structures: $30 \mathrm{~s}$ to $2 \mathrm{~min}$ for each pulse and purge step and 10-20 s exposure with hold times between 1 and 4 min, for the two methods, respectively. While both methods successfully replicated the 3D network morphology, the stop-flow method was more practical because pulsing the precursors for up to $2 \mathrm{~min}$ per cycle led to a precursor consumption of up to $240 \mathrm{~min}$ per sample, whereas the stop-flow method only required 20-40 min precursor consumption time, while exposing the template to the precursor for a similar time period as in the continuous flow method. The ALD parameters of the samples shown in the figures are summarized in Table 1.

The careful analysis of Figure 2 reveals the details of ALD replication. Annealing above $400{ }^{\circ} \mathrm{C}$ or $\mathrm{O}_{2}$-plasma treatment removed the polymer network, revealing gyroid or worm-like $\mathrm{ZnO}$ morphologies. In the cases when ALD deposition did not

Table 1. Summary of the ALD parameters used to fabricate the samples shown in the figures.

\begin{tabular}{|c|c|c|c|c|c|c|c|}
\hline Sample & No. of cycles & DEZ Pulse & Hold & Purge & $\mathrm{H}_{2} \mathrm{O}$ pulse & Hold & Purge \\
\hline \multirow[t]{4}{*}{ Figures 2 and 4} & $1-30$ & $30 \mathrm{~s}$ & - & $30 \mathrm{~s}$ & $30 \mathrm{~s}$ & - & $30 \mathrm{~s}$ \\
\hline & $31-60$ & $30 \mathrm{~s}$ & $30 \mathrm{~s}$ & $30 \mathrm{~s}$ & $30 \mathrm{~s}$ & $30 \mathrm{~s}$ & $30 \mathrm{~s}$ \\
\hline & $61-90$ & $30 \mathrm{~s}$ & $1 \mathrm{~min} 30 \mathrm{~s}$ & $1 \mathrm{~min} 30 \mathrm{~s}$ & $30 \mathrm{~s}$ & $1 \mathrm{~min} 30 \mathrm{~s}$ & $1 \mathrm{~min} 30 \mathrm{~s}$ \\
\hline & $91-110$ & $30 \mathrm{~s}$ & $2 \min 30 s$ & $2 \min 30 s$ & $30 \mathrm{~s}$ & $2 \min 30 s$ & $2 \mathrm{~min} 30 \mathrm{~s}$ \\
\hline \multirow[t]{3}{*}{ Figures 3 and 5} & $1-30$ & $15 \mathrm{~s}$ & $45 \mathrm{~s}$ & $1 \mathrm{~min}$ & $15 \mathrm{~s}$ & $45 \mathrm{~s}$ & $1 \mathrm{~min}$ \\
\hline & $31-60$ & $15 \mathrm{~s}$ & $1 \mathrm{~min} 30 \mathrm{~s}$ & $1 \mathrm{~min} 30 \mathrm{~s}$ & $15 \mathrm{~s}$ & $1 \mathrm{~min}$ & $1 \mathrm{~min}$ \\
\hline & $61-75$ & $15 \mathrm{~s}$ & $2 \min 30 s$ & $2 \min 30 s$ & $15 \mathrm{~s}$ & $2 \min 30 s$ & $2 \min 30 s$ \\
\hline
\end{tabular}




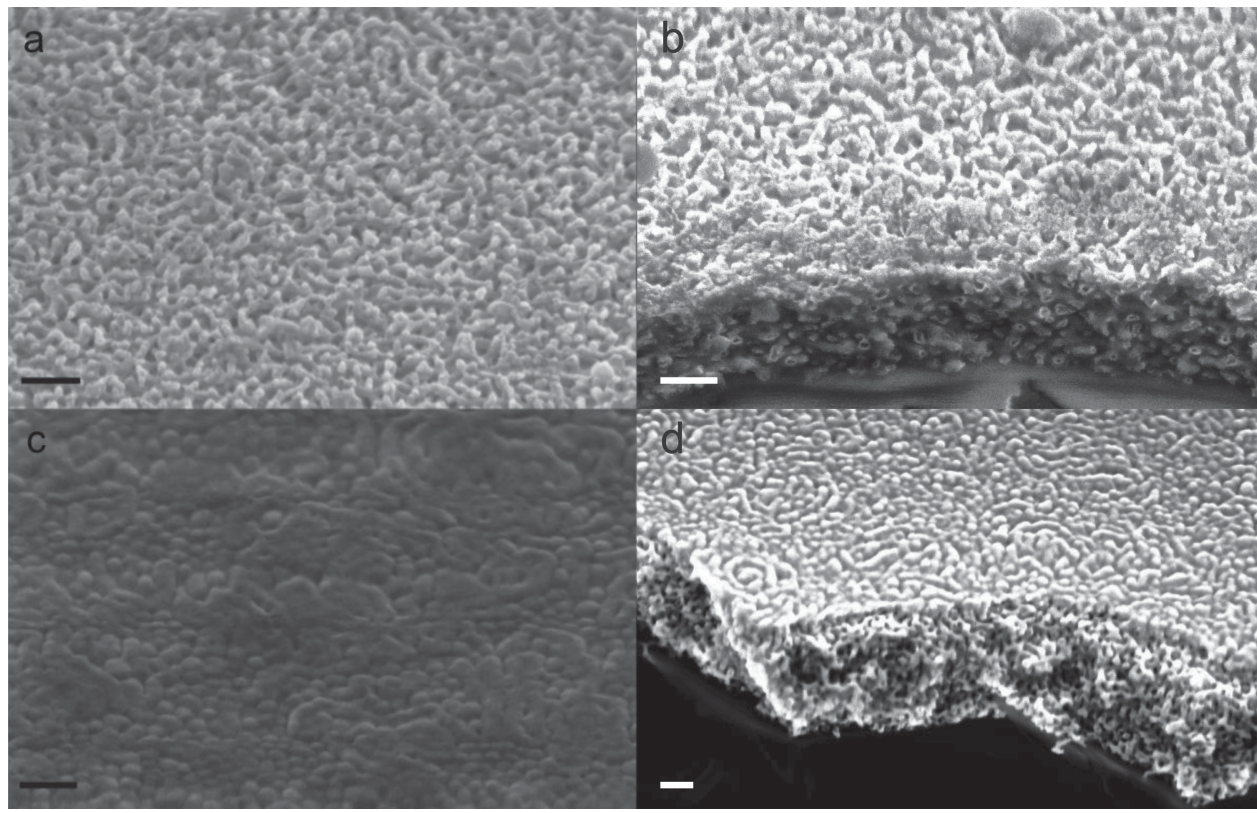

Figure 4. ALD deposited ZnO replica of porous polymer templates: a) top layer, b) cross-section after 30 cycles, and c,d) after 75 cycles. The scale bars correspond to $200 \mathrm{~nm}$.

extend down to the substrate (Figure $2 \mathrm{~b}$ ), polymer removal did not destroy the replica, which settled onto the substrate, fully preserving the template-imposed morphology (Figure 2c). Further evidence for incomplete ALD replication can be seen in Figure 2e. Close to the substrate, the network struts are voided (void diameter $<5 \mathrm{~nm}$ ) indicating that the pores near the free surface have closed before the ALD process further down was complete. Incomplete penetration of $\mathrm{ZnO}$ through the entire depth of the template is a consequence of the ALD parameters, including the precursor partial pressure, the exposure time, the template aspect ratio, and the chemistry of the template surface. ${ }^{[14,24]}$ In addition, sufficient purge time for each half-cycle is crucial for the removal of the unreacted precursor and the reaction byproducts.

The interplay of these parameters has been experimentally and theoretically studied in high-aspect-ratio systems, typically with pore widths $>100 \mathrm{~nm} ;{ }^{[14-16]}$ often, pore-blocking and nonuniform coatings have been observed. ${ }^{[25]}$ The present system differs, however, from 1D model architectures. Our 3D bicontinuous networks have more complex morphologies of interconnected channels. The high specific surface area (compared to $1 \mathrm{D}$ channels) may require longer pulse and purge times to achieve complete saturation of the substrate surface and removal of the reaction products. ${ }^{[14-16]}$ Furthermore, the small feature size of $30 \mathrm{~nm}$ may complicate the control of $\mathrm{ZnO}$ crystallization. A confinement diameter that is comparable to the size of a critical nucleation seed may either inhibit $\mathrm{ZnO}$ crystallization or cause pore blockage by uncontrolled crystal nucleation. The latter is confirmed by XRD results, observing $8 \mathrm{~nm}$ $\mathrm{ZnO}$ crystallites in the as-deposited gyroid matrix (see below).

Crystallite or cluster formation is enhanced for surfaces, which are only sparsely covered by groups that can react with the ALD precursor. For the diethyl zinc precursor used in this study, a dense surface coverage of the polymer scaffold by $\mathrm{OH}$ groups is therefore essential. ${ }^{[26]}$ In the PS-PI self-assembled template, $\mathrm{OH}$ and $\mathrm{COOH}$ groups are created during UV exposure, which also degrades the PI. ${ }^{[20]}$ The SEM image shown in Figure 4 confirms the formation of a uniform initial coating and the absence of cluster formation on the $10 \mathrm{~nm}$ length scale.

Void formation in Figure 2 was insensitive to changes in the ALD cycle parameters (e.g., an increase in the exposure duration by a factor of two). Careful analysis of Figure 5 shows that the pores at the top of the film have closed after 65 cycles (rather than the calculated 80-90 cycles). Assuming true atomic layer deposition, this corresponds to a deposition of 10-15 nm, leaving a 3-7 $\mathrm{nm}$ core unfilled. We propose two possible reasons for the incomplete pore filling of Figure 2. Firstly, the long exposure time to the ALD precursor, which is necessary because of the large aspect ratio of the network, may result in multilayer adsorption in the pores close to the surface and therefore more rapid $\mathrm{ZnO}$ layer growth. Secondly, the degradation of PI with UV light is less efficient deeper inside the film (up to $48 \mathrm{~h}$ UV exposure followed by $48 \mathrm{~h}$ ethanol dissolution are reportedly required to completely remove the PI). ${ }^{[27]}$ This may result in incomplete degradation and/or alteration of the surface chemistry and therefore an incomplete ALD process. Nevertheless, ALD infiltration into up to $5 \mu \mathrm{m}$ thick templates was achieved (Figure 5).

\subsubsection{Deposition Temperature}

The long cycle times required by the high aspect ratio pores result in stringent requirements concerning the temperature stability of the polymer matrix. This was assessed by annealing the templates in vacuum for up to $24 \mathrm{~h}$ in temperatures up to $120{ }^{\circ} \mathrm{C}$. The cross-linked PS morphology was found to withstand up to $110{ }^{\circ} \mathrm{C}$, above which a collapse of the polymer structure was observed. This lies well within the temperature 


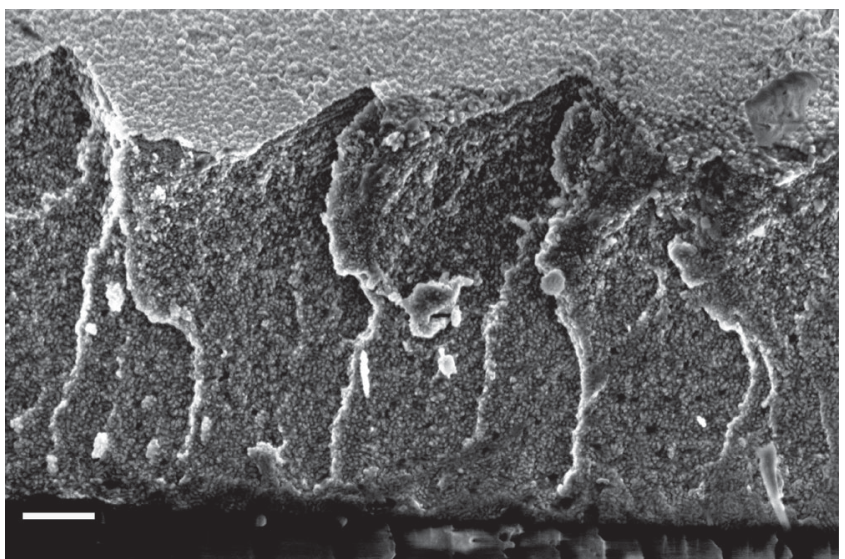

Figure 5. Cross-sectional SEM image of a worm-like ZnO-PS hybrid. ZnO was deposited conformally onto a $5 \mu \mathrm{m}$ thick worm-like PS template. The scale bar corresponds to $1 \mu \mathrm{m}$.
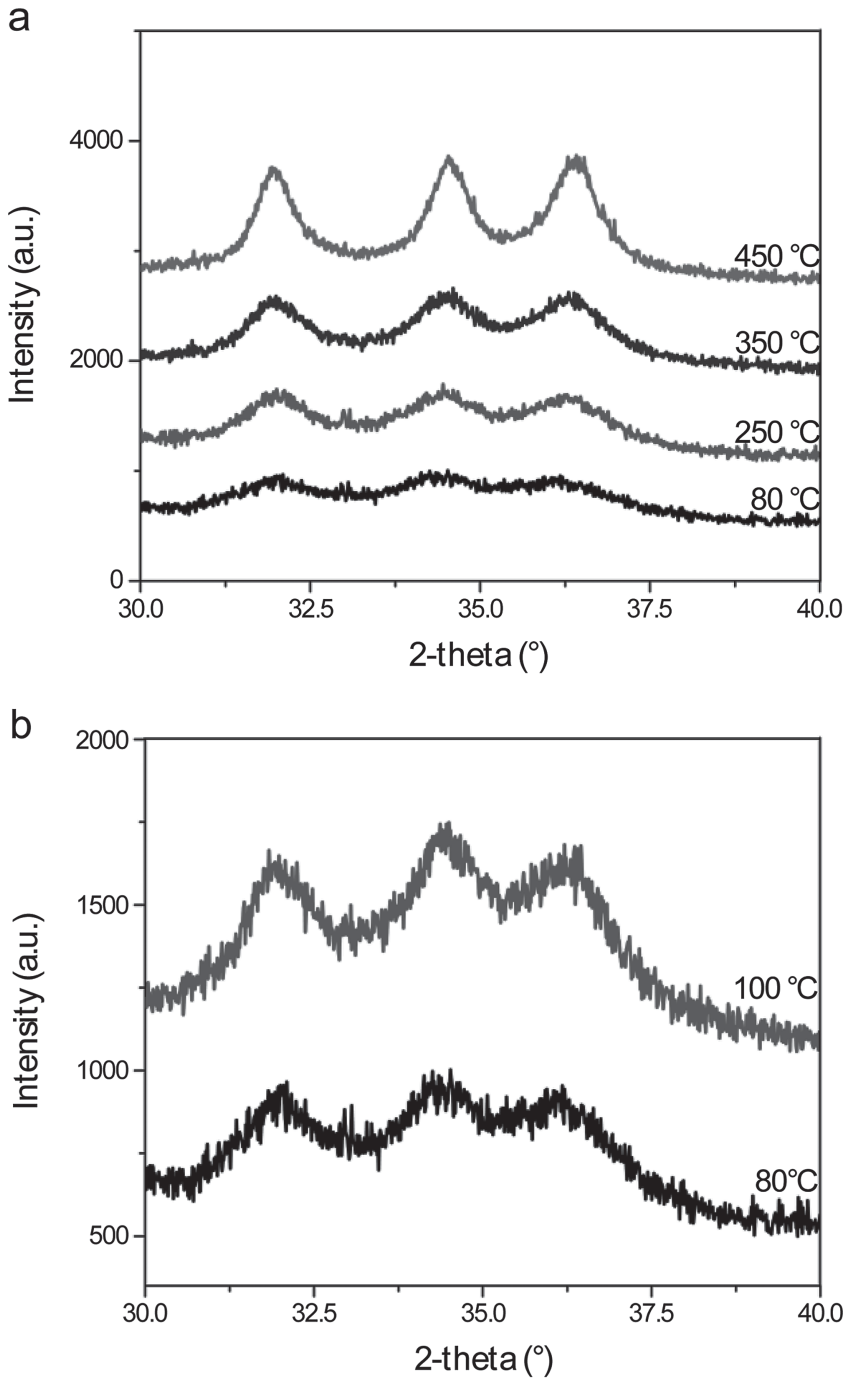

Figure 6. WAXS characterization of mesoporous $\mathrm{ZnO}$ : a) effect of post thermal annealing after ALD deposition at $80^{\circ} \mathrm{C}$, and b) as-deposited, without further annealing. window for ALD ZnO deposition of $80-150{ }^{\circ} \mathrm{C},{ }^{[21]}$ which is limited by a lack of surface reactivity (low temperature) and precursor dissociation. The lowest possible deposition temperature was therefore chosen. A higher temperature of $100{ }^{\circ} \mathrm{C}$ yielded very similar results (Figure $6 \mathrm{~b}$ ).

\subsubsection{Characterization by X-Ray Diffraction}

The replicated $\mathrm{ZnO}$ was characterized by wide-angle $\mathrm{x}$-ray scattering (WAXS) to examine $\mathrm{ZnO}$ crystallization as a function of the post-deposition annealing temperature. Figure 6a shows the spectra of films annealed at 250,350 , and $450{ }^{\circ} \mathrm{C}$. Before annealing, the polymer was removed by an $\mathrm{O}_{2}$-plasma treatment. The peaks in the spectra correspond to wurtzite $\mathrm{ZnO} .^{[28]}$ While the as-deposited film has the clear signature of $\mathrm{ZnO}$ crystallinity, the peaks are broad, indicating very small crystallites and possibly some amorphous content. The initial $\mathrm{ZnO}$ crystallinity does not depend on the ALD deposition temperature, as shown in Figure 6b. Annealing at higher temperatures sharpened the WAXS peaks. Using the Scherrer equation, crystallite sizes of $13 \mathrm{~nm}$ for 250 and $350{ }^{\circ} \mathrm{C}$, and $25 \mathrm{~nm}$ for $450{ }^{\circ} \mathrm{C}$ were found. While a detailed study of the $\mathrm{ZnO}$ crystallisation kinetics is outside the scope of this study, the increase of crystallite size in the BCP confinement with annealing temperature mirrors the results obtained for $\mathrm{TiO}_{2}$, where the crystallite size increased with increasing annealing temperature $\left(400-700^{\circ} \mathrm{C}\right)$ from 12 to $28 \mathrm{~nm} \cdot{ }^{[29]}$ Crystallite sizes in the $20 \mathrm{~nm}$ range were reported to optimize performance in hybrid solar cells. ${ }^{[30]}$

While the structural characterization of replicated gyroids has been carried out before, ${ }^{[3]}$ less is known about the wormlike morphology. Figure 7a shows grazing-incidence smallangle scattering (GISAXS) spectra of a voided worm-like polystyrene template. This spectrum shows structure at lateral positions, which correspond to a lattice spacing of ca. $57 \mathrm{~nm}$. These are quantified by the 1D intensity profile in Figure $7 \mathrm{~b}$ that was extracted along $q_{\mathrm{y}}$ and averaged over the $q_{\mathrm{z}}$-range where the transmission function of the polymer film has a maximum. Lorentz functions were fitted to the three scattering peaks that correspond to three orders of Bragg reflections arising from the pore morphology in the film. The three reflections have $q$ ratios of $1: \sqrt{4}: \sqrt{7}$, which is characteristic for a hexagonally packed assembly of cylinder segments. The Bragg rods are bent inwards, which we attribute to tilting of the cylinder segments away from a fully perpendicular orientation; i.e., the scattering signal arises from randomly oriented cylinders. The presence of higher-order Bragg reflections points to the formation of this locally symmetric randomly oriented morphology within the entire film.

The GISAXS spectrum in Figure 7c of the ALD ZnO replica shows lateral Bragg reflections at positions which correspond to a lattice spacing of $63 \mathrm{~nm}$. Figure $7 \mathrm{~d}$ shows the $q_{\mathrm{z}}$-averaged $1 \mathrm{D}$ intensity profile along $q_{\mathrm{y}}$ at maximal transmission (bottom), together with the profile extracted at $q_{\mathrm{z}} \approx 0.053 \AA^{-1}$ (second from bottom). The Bragg rods at $q_{y}=2 \pi / d_{\text {cyl }}$ are vertical, which is indicative of laterally ordered cylinder segments. The scattering features at $q_{z} \approx 0.053 \AA^{-1}$ can be attributed to cylinder segments distributed along $q_{z}$; i.e., the cylinder spacing 

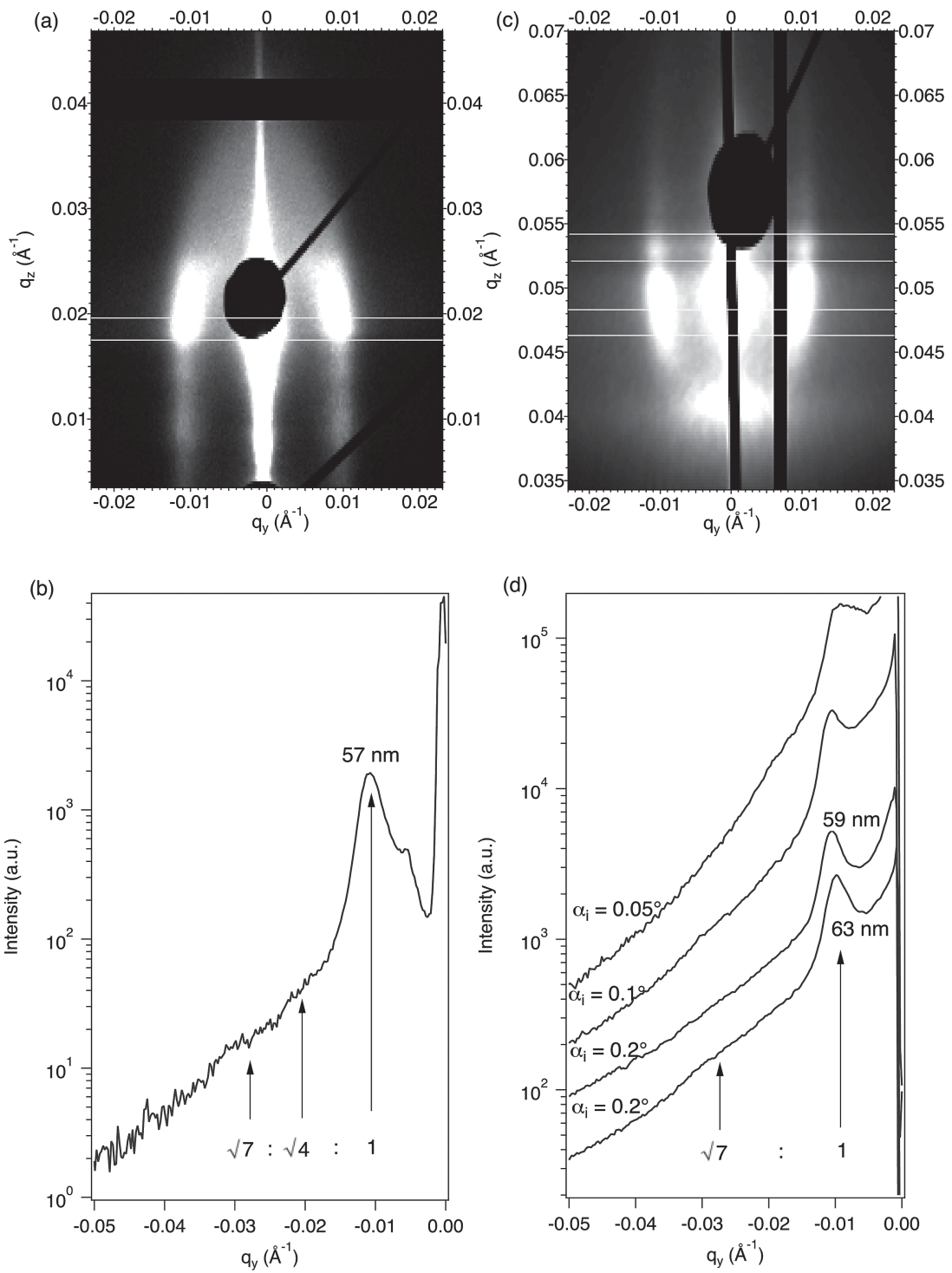

Figure 7. a) GISAXS pattern of the worm-like polystyrene template film showing bent Bragg rods, taken at an incident angle of $0.185^{\circ}$, and c) corresponding 1D GISAXS intensity profile along $q_{y}$. b) GISAXS pattern of the resulting ZnO film after annealing at $450{ }^{\circ} \mathrm{C}$ followed by ICP etching of the top compact layer, taken at and angle of incidence of $0.2^{\circ}$, and d) corresponding ID GISAXS intensity profiles along $q$. The spectra for incident angles of $0.1^{\circ}$ and $0.05^{\circ}$ are also shown, shifted vertically for clarity. The horizontal lines in (a) and (c) indicate the locations of the spectra in (c) and (d), respectively. The arrows indicate the scattering peaks corresponding to the Bragg reflections arising from cylinder-like structures.

is not constant along $q_{\mathrm{z}}$ (with a periodic variation of a few $\mathrm{nm}$ ) or the cylinder segments are slightly tilted. This observation is further supported by the presence of the first- and third-order Bragg peaks, with a missing second-order reflection (bottom curve). This points to an asymmetry of the cylinder structure, which is particularly pronounced at the interface with the substrate.

The $\mathrm{ZnO}$ film was additionally probed at further two incident angles of $0.1^{\circ}$ and $0.05^{\circ}$, which give information on the morphology close to the film surface. These spectra do not show the cylinder asymmetry and the variation of the Bragg rods along $q_{z}$ is also absent in the 2D GISAXS spectra (see the Supporting Information).

\section{1.5. X-ray Photoemission Spectroscopy (XPS)}

The chemical composition of the film was probed by XPS. Figure 8a shows the Zn $2 \mathrm{p}$ and $\mathrm{O} 1 \mathrm{~s}$ spectra of as-deposited and $400{ }^{\circ} \mathrm{C}$-annealed films. The $\mathrm{Zn} 2 \mathrm{p} 3$ peak appears at $1022.4 \mathrm{eV}$, in good agreement with previous reports for $\mathrm{ZnO} .{ }^{[31]}$ The $\mathrm{O}$ 1s peak can be deconvoluted into a low-bindingenergy peak at $530.9 \mathrm{eV}$ and a high-bindingenergy peak at $532.4 \mathrm{eV}$. The low binding energy peak is assigned to $\mathrm{O}-\mathrm{Zn}$ oxygen atoms, while the high binding energy peak arises from $\mathrm{O}-\mathrm{H}$ groups. The percentages are the relative contribution of each peak, showing that annealing increases the percentage of $\mathrm{O}-\mathrm{Zn}$ atoms in the film. The surface scan also revealed the existence of adventitious carbon (not shown here) which accounted for $10 \%$ of the atomic composition.

An XPS profile measured the composition of the mesoporous material across the thickness of the film. Figure $8 \mathrm{~b}$ shows the variation of the $\mathrm{Zn} \mathrm{2p}, \mathrm{O}$ 1s, C 1s, and Si 2p (Si and $\mathrm{SiO} 2)$ signals with etching time. The spectrum of the top surface in Figure 8a was not included in the depth profile because of the $10 \%$ carbon contamination. The depth profile shows that the composition of the $\mathrm{ZnO}$ gyroid (I) is uniform up to the $\mathrm{ZnO}$ compact layer (II) on the $\mathrm{SiO} 2 / \mathrm{Si}$ substrate (III and IV). Additionally, this result shows that that the mesoporous layer is carbon-free, demonstrating the full removal of the polymer template. The $\mathrm{ZnO}$ composition throughout the film is not stochiometric but highly oxygen deficient, as expected for a $\mathrm{ZnO}$ layer.

\subsubsection{Hybrid Photovoltaic Cell}

To demonstrate the potential of application of the ALD-generated mesoporous $\mathrm{ZnO}$ layer for hybrid photovoltaics, a polymer/mesoZnO solar cell was fabricated. For this purpose, a worm-like mesoporous layer was deposited onto a conductive pre-patterned ITO substrate and infiltrated with poly(3-hexylthiophene) (P3HT) polymer. The worm-like $\mathrm{ZnO}$ structure was chosen because of the better control over film thickness and uniformity compared to the gyroid template. Figure 9a and b show the external quantum efficiency (EQE) of the photovoltaic device and its current-voltage $(J-V)$ characteristic under solar-simulator illumination, respectively. The device performance parameters including the short-circuit current $J_{\mathrm{sc}}$, the open-circuit voltage $V_{\text {oc }}$, the fill factor FF, and the power conversion effciency PCE are shown in the inset of Figure 9b. 
a
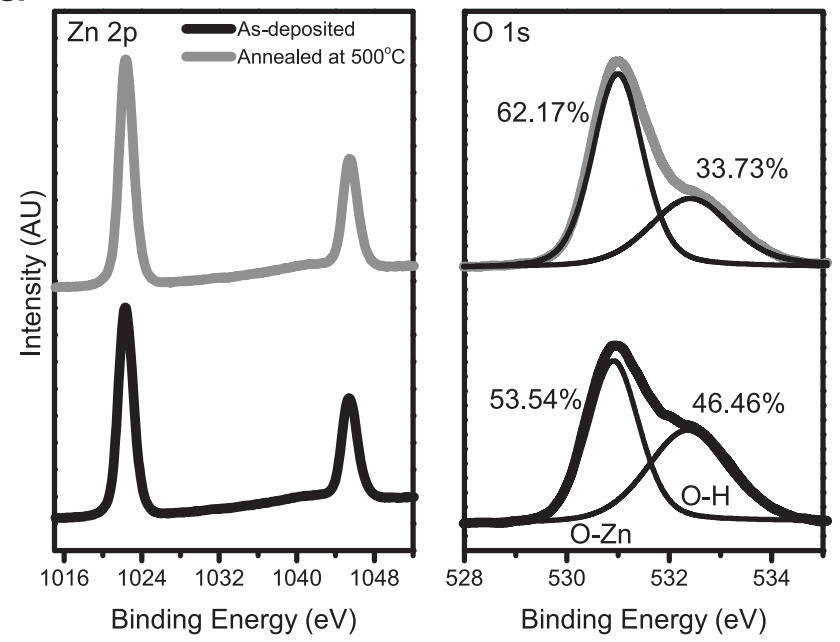

b

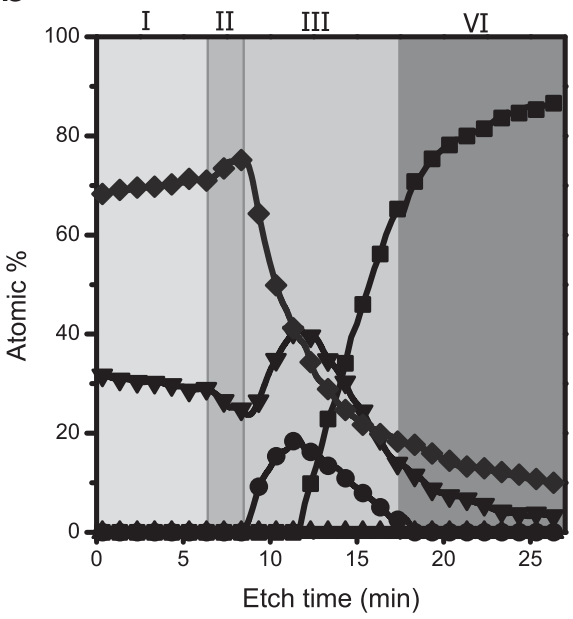

I. Gyroid $\mathrm{ZnO}$

II. Compact $\mathrm{ZnO}$

III. SiOx

IV. Si substrate

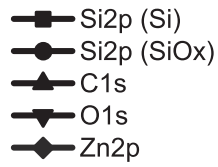

Figure 8. XPS spectra of: a) Zn 2p and O 1s on as-deposited and annealed films, and b) depth profile of an annealed film.

The short-circuit current of the device $\left(U_{\mathrm{sc}}=2.38 \mathrm{~mA} \mathrm{~cm}^{-2}\right)$ is significantly improved compared to a bilayer device comprised of non-porous $\mathrm{ZnO}$ and P3HT $\left(U_{\mathrm{sc}}=0.47 \mathrm{~mA} \mathrm{~cm}^{-2}\right)$ in the otherwise same device architecture. ${ }^{[32]}$ The increased effective surface area in the mesoporous layer increases exciton dissociation at the $\mathrm{ZnO} / \mathrm{P} 3 \mathrm{HT}$ interface and hence increases the photocurrent. The open-circuit voltage $\left(V_{o c}\right)$ of the $\mathrm{ZnO} /$ P3HT couple depends on the $\mathrm{ZnO}$ work function and the bandgap. The value of $V_{\mathrm{oc}}=0.19 \mathrm{~V}$ of our device is much below the $V_{o c}=0.43 \mathrm{~V}$ that was found for P3HT/ZnO nanowire devices. ${ }^{[28]}$ This reduced value of $V_{\text {oc }}$ points to the existence of sub-bandgap states on the $\mathrm{ZnO}$ surface, which may arise from a surface chemistry that differs from bulk $\mathrm{ZnO}$. Further optimization of the ALD-generated $\mathrm{ZnO}$ is required to increase the open-circuit voltage of the device. Finally, the relatively low fill factor $(\mathrm{FF})$ of the device suggests that charges are not extracted efficiently from the device. This might either be due to resistance within the mesoporous structure and/or connectivity the solid $\mathrm{ZnO}$ and/or $\mathrm{WO}_{3}$ blocking layers. It is likely that the main cause limiting the fill factor is the lack of control of the surface roughness during the ICP etching of the compact layer. Further studies aiming to improve $V_{\mathrm{oc}}$ and FF are ongoing. Given the scope for optimization, the results of Figure 9 are promising. Note that $\mathrm{ZnO}$-polymer hybrid solar cells typically have power conversion efficiencies below $1 \%,{ }^{[33]}$ and that the performance of our photovoltaic device is comparable to previous reports of $\mathrm{P} 3 \mathrm{HT} / \mathrm{ZnO}$ nanocrystal mesoporous layers. ${ }^{[30]}$

\section{Conclusion}

ALD deposition of $\mathrm{ZnO}$ into a nanoporous polymer matrix allows the fabrication of well-defined, 3D ZnO scaffolds with 20-40 $\mathrm{nm}$ wide struts. While similar morphologies of other metal oxides have been created using a range of deposition techniques, the controlled manufacture of 3D interconnected $\mathrm{ZnO}$ skeletons is remarkable because the low crystallization temperature of $\mathrm{ZnO}$ makes the molding of $\mathrm{ZnO}$ into design morphologies very difficult.

Two different morphologies based on the self-assembly of a PS-PI block copolymer are presented. The carefully annealed polymer phase morphology leads to a highly periodic double gyroid morphology, while a worm-like morphology was observed upon rapid quenching. Both morphologies consisted of a well-defined strut network with interconnected pores. While the highly periodic $\mathrm{ZnO}$ gyroid is conceptionally attractive, it requires delicate processing and a longer preparation time. The worm-like structure, on the other hand, is robust to generate and more controllable, which could be beneficial for production at a larger scale.

The key for the realization of these structures is to bypass the rapid crystallization of $\mathrm{ZnO}$ during material deposition. Since the ALD principle relies on surface-limited reactions leading to the conformal coating of a 3D surface, good control over the surface chemistry of the mold is imperative. For the present system, this implies a dense coverage of the pore surface with $\mathrm{OH}$ groups. Because of the pore size of only $30 \mathrm{~nm}$, this requirement is especially stringent since the formation of even the smallest crystallites leads to pore blockage.

The fabricated films were characterized using XPS, WAXS, GISAXS, and SEM, which confirmed deposition of wurtzite $\mathrm{ZnO}$ throughout the film. The as-deposited $\mathrm{ZnO}$ (at $80{ }^{\circ} \mathrm{C}$ ) onto the polymer substrate was (partially) nanocrystalline, and crystallites grew larger upon post annealing at high temperatures. The structure showed thermal stability up to $550^{\circ} \mathrm{C}$. The average pore width of approximately $30 \mathrm{~nm}$ is ideal for exciton dissociation in hybrid photovoltaic devices. Preliminary results of a P3HT/ZnO device based on the worm-like morphology demonstrate the promise of this material for photovoltaic applications.

The manufacture of a ZnO-based solar cell showed the feasibility of the integration of the 3D mesostructured $\mathrm{ZnO}$ networks into devices. More promising than the direct function of $\mathrm{ZnO}$ in photovoltaics is its use as electrode material in solar cells, ${ }^{[34,35]}$ in organic LEDs and lasers, and as a highly sensitive gas sensor. ${ }^{[36]}$ 
a
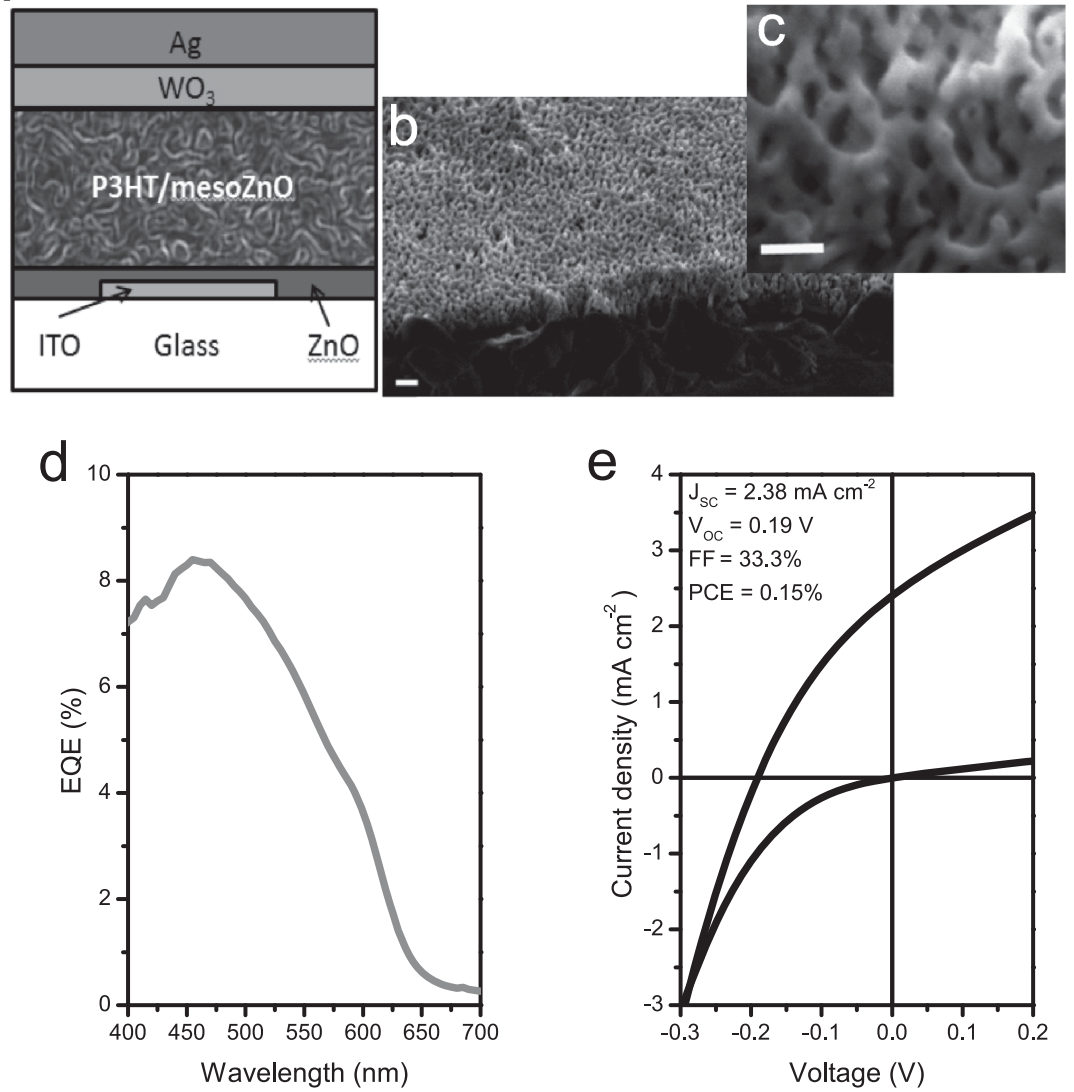

e

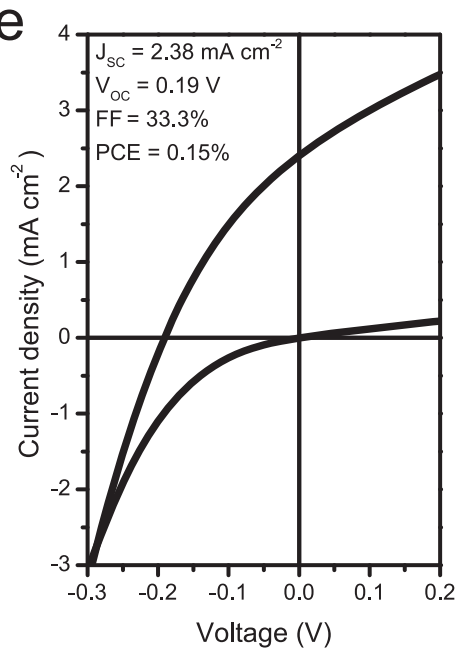

Figure 9. Summary of the architecture and performance of a $\mathrm{ZnO} / \mathrm{P} 3 \mathrm{HT}$ device built using a worm-like ZnO film of $250 \mathrm{~nm}$ thickness. a) Schematics of the device. b,c) SEM images of the worm-like $\mathrm{ZnO}$ layer at two magnifications (the scale bars correspond to $100 \mathrm{~nm}$ ). d) External qantum efficiency, and e) current-voltage characteristic of the device; the lower line shows the performance of a $\mathrm{ZnO} / \mathrm{P} 3 \mathrm{HT}$ bilayer device.

\section{Experimental Section}

Template Fabrication: ${ }^{[18,19]}$ The polymers used for template fabrication were polystyrene $\left(45 \mathrm{~kg} \mathrm{~mol}^{-1}\right)$-block-polyisoprene $\left(39 \mathrm{~kg} \mathrm{~mol}^{-1}\right.$; PS-b-PI), purchased from Polymer Source Inc., Canada, and polystyrene $(10 \mathrm{~kg}$ $\mathrm{mol}^{-1}$; PS), purchased from Sigma Aldrich. PS- $b$-PI and PS were mixed to result in $65 \%$ volume fraction of PS and dissolved in toluene. For the self-assembled gyroid structure, $20 \mu \mathrm{L}$ of solution was dropcast onto a substrate ( $\mathrm{Si}$, ITO, or glass) of $1.2 \mathrm{~cm} \times 1.2 \mathrm{~cm}$. A PTFE film of $1 \mathrm{~cm} \times 1 \mathrm{~cm}$ was placed onto the middle of the drop and the film was placed into a sealed chamber containing toluene vapor at $4{ }^{\circ} \mathrm{C}$ for up to $7 \mathrm{~d}$. For the worm-like morphology, $60 \mu \mathrm{L}$ of the mixed polymer solution was spin-coated onto a substrate at $1000 \mathrm{rpm}$ for $90 \mathrm{~s}$. The film was then taken out of the chamber and left in air at room temperature for an additional $24 \mathrm{~h}$ before exposure to UV light $(254 \mathrm{~nm})$ for $12 \mathrm{~h}$ in order to degrade the polyisoprene block. The degradation product was then removed by placing the film in ethanol solution for $15 \mathrm{~h}$. In order to minimize peeling and cracking of the film, the sample was placed upside down on a lint-free tissue and dried.

$\mathrm{ZnO}$ Replication: A Beneq TFS200 system was used for ALD. The ZnO precursors were diethyl zinc $\left(\mathrm{C}_{2} \mathrm{H}_{5}\right)_{2} \mathrm{Zn}$, purchased from $\mathrm{ABCR} \mathrm{GmbH}$, and deionized water $\left(\mathrm{H}_{2} \mathrm{O}\right)$. Between 65 and 250 deposition cycles were used. The optimized protocol for the continuous flow method consisted of pulse/purge times of $30 \mathrm{~s}$ for the first 30 cycles, 1 min for the following 40 cycles, and $2 \mathrm{~min}$ for the last 30 cycles. A typical half-cycle in the stop-flow method consisted of a $10 \mathrm{~s}$ pulse followed by $1 \mathrm{~min}$ hold time with the vacuum and nitrogen flow off, followed by a 1 min purge time. $\mathrm{ZnO}$ deposition was normally carried out at $80^{\circ} \mathrm{C}$, but depositions at 100 and $120^{\circ} \mathrm{C}$ were also made for comparison. The ALD parameters of the samples shown in the figures are summarized in Table 1.

Removal of the PS Template: The deposited $\mathrm{ZnO}$ polymer hybrid was exposed to either an oxygen plasma (Diener Plasma Etcher) or calcination at temperatures above $400{ }^{\circ} \mathrm{C}$. Depending on the thickness of the mesoporous template, a plasma duration 15 to 45 min was required. Hightemperature removal of PS was achieved by heating $\left(10{ }^{\circ} \mathrm{C} \mathrm{min}^{-1}\right)$ to a temperature above $450{ }^{\circ} \mathrm{C}$ followed by annealing for $2 \mathrm{~h}$ in air.

Removal of the Compact $\mathrm{ZnO}$ Top Layer: An Oxford Instrument inductively coupled plasma etcher was used to etch-off the top nonporous $\mathrm{ZnO}$ layer that has formed by ALD. 6 min of etching removed the $30 \mathrm{~nm} \mathrm{ZnO}$. The etchant gases were $\mathrm{CHF}_{3}(50 \mathrm{ccm})$ and $\operatorname{Ar}(25 \mathrm{ccm})$ using an RF power of $100 \mathrm{~W}$ and a forward power $1550 \mathrm{~W}$.

$X$-Ray Diffraction: Wide-angle $\mathrm{x}$-ray scattering (WAXS) measurements, were carried out using a Bruker D8 diffractometer. The samples were prepared on a $\mathrm{Si}$ substrate. Grazing-incidence small-angle scattering (GISAXS) measurements were performed at beamline P03 ${ }^{[37]}$ (PETRA III), HASYLAB at DESY in Hamburg, Germany. At P03 the wavelength was $1.09 \mathrm{~A}$. The beam was focused by beryllium compound refractive lenses to a size of $31 \mu \mathrm{m} \times 22 \mu \mathrm{m}$ (horizontal $\times$ vertical) at the sample position, with an incident angle of $0.185^{\circ}$ for the polystyrene template, and $0.05^{\circ}, 0.1^{\circ}$, and $0.2^{\circ}$ for the resulting $\mathrm{ZnO}$ film. A Pilatus $1 \mathrm{M}$ area detector was used for the detection of the scattered intensity. The pixel sizes were $172 \mu \mathrm{m} \times 172 \mu \mathrm{m}$. The sampledetector distances were $4.260 \mathrm{~m}$ for polystyrene and $3.651 \mathrm{~m}$ for $\mathrm{ZnO}$. The sample was moved out of the beam after each measurement to avoid beam damage. The $q$-space calibration was performed by fitting the characteristic scattering signal arising from $400 \mathrm{~nm}$ colloids. The conversion of the 2D images from pixels to $q$-values as well as the construction of 1D profiles and the peak fitting were carried out using a self-written GISAXS Igor Pro analysis package.

$X$-ray Photoemission Spectroscopy Measurements: The gyroid ZnO samples were fabricated on an oxide-covered silicon wafer which was transferred into the ultrahigh vacuum chamber of a ESCALAB 250Xi for XPS measurements. The measurements were carried out using a XR6 monochromated Alk $\alpha$ X-ray source $(h v=1486.6 \mathrm{eV})$ with a $650 \mu \mathrm{m}$ spot size. For XPS depth profiling, the sample was etched using an $\mathrm{Ar}^{+}$ion beam with an energy of $3000 \mathrm{eV}$.

Photovoltaic Device Fabrication: A worm-like $\mathrm{ZnO}$ mesoporous film was fabricated on a prepatterned ITO/glass substrate as described above. Poly (3-hexylthiophene) ( $\mathrm{P} 3 \mathrm{HT}$; from Reike Metals) polymers were dissolved in anhydrous chlorobenzene and spin-coated onto the $\mathrm{ZnO}$ mesoporous layer. The samples were then transferred into a thermal evaporation chamber for $\mathrm{WO}_{3}(10 \mathrm{~nm}), \mathrm{Ag}(30 \mathrm{~nm})$, and $\mathrm{Al}(60 \mathrm{~nm})$ deposition under high vacuum $\left(10^{-6} \mathrm{mbar}\right)$. Finally, the devices were post-annealed at $140^{\circ} \mathrm{C}$ for $10 \mathrm{~min}$.

Photovoltaic Performance Characterization: For external quantum effciency (EQE) measurements (in air) a $250 \mathrm{~W}$ tungsten halogen lamp and an Oriel Cornerstone 130 monochromator were used. The measurements were performed as a function of wavelength at an intensity of $1 \mathrm{~mW} \mathrm{~cm}{ }^{-3}$. To measure the $J-V$ curve of the device under AM1.5 conditions, an ABET Solar 2000 solar simulator was used. In order to obtain reliable data, a spectral mismatch correction was carried out using a calibrated and certified inorganic solar cell. 


\section{Supporting Information}

Supporting Information is available from the Wiley Online Library or from the author.

\section{Acknowledgements}

The authors thank S. Vignolini for her invaluable help and P. MüllerBuschbaum for providing the GISAXS beamtime. We acknowledge the Nokia Research Centre (Cambridge, UK) and the EPSRC for funding. Parts of this research were carried out at the light source PETRA III at DESY. DESY is a member of the Helmholtz Association (HGF).

Received: July 2, 2013 Published online: September 3, 2013

[1] A. B. Djurišić,, X. Chen, Y. H. Leung, A. M. C. Ng, J. Mater. Chem. 2012, 22, 6526.

[2] M. C. Gwinner, Y. Vaynzof, K. K. Banger, P. K. H. Ho, R. H. Friend, H. Sirringhaus, Adv. Funct. Mater. 2010, 20, 3457.

[3] E. Crossland, M. Kamperman, M. Nedelcu, C. Ducati, U. Wiesner, D. Smilgies, G. Toombes, M. Hillmyer, S. Ludwigs, U. Steiner, Nano Lett. 2008, 9, 2807.

[4] Q. Zhang, C. S. Dandeneau, X. Zhou, G. Cao, Adv. Mater. 2009, 21, 4087.

[5] J. Qiu, M. Guo, X. Wang, ACS Appl. Mater. Interfaces 2011, 3, 2358.

[6] S. Ko, D. Lee, H. Kang, K. Nam, J. Yeo, S. Hong, C. Grigoropoulos, H. Sung, Nano Lett. 2011, 11, 666.

[7] M. Scharrer, X. Wu, A. Yamilov, H. Cao, Appl. Phys. Lett. 2005, 86, 151113.

[8] T. Wagner, T. Waitz, J. Roggenbuck, M. Fröba, C. D. Kohl, M. Tiemann, Thin Solid Films 2007, 515, 8360.

[9] S. Lepoutre, B. Julián-López, C. Sanchez, H. Amenitsch, M. Linden, D. Grosso, J. Mater. Chem. 2010, 20, 537.

[10] T. Hashimoto, Y. Nishikawa, K. Tsutsumi, Macromolecules 2007, 40, 1066.

[11] E. Crossland, P. Cunha, S. Scroggins, S. Moratti, O. Yurchenko, U. Steiner, M. Hillmyer, S. Ludwigs, ACS Nano 2010, 4, 962.

[12] P. Yang, D. Zhao, D. I. Margolese, B. F. Chmelka, G. D. Stucky, Chem. Mater. 1999, 11, 2813.

[13] H. Hsueh, R. Ho, Langmuir 2012, 28, 8518.

[14] R. Gordon, D. Hausmann, E. Kim, J. Shepard, Chem. Vapor Deposition 2003, 9, 73 .
[15] S. K. Karuturi, L. Liu, L. T. Su, A. Chutinan, N. P. Kherani, T. K. Chan, T. Osipowicz, A. I. Y. Tok, Nanoscale 2011, 3, 4951.

[16] J. Elam, D. Routkevitch, P. Mardilovich, S. George, Chem. Mater. 2003, 15, 3507.

[17] Y. Wang, Y. Qin, A. Berger, E. Yau, C. He, L. Zhang, U. Gösele, M. Knez, M. Steinhart, Adv. Mater. 2009, 21, 2763.

[18] A. S. Finnemore, M. R. J. Scherer, R. Langford, S. Mahajan, S. Ludwigs, F. C. Meldrum, U. Steiner, Adv. Mater. 2009, 21, 3928.

[19] M. Scherer, Diplomarbeit, University of Konstanz, 2009.

[20] S. Ndoni, L. Li, L. Schulte, P. P. Szewczykowski, T. W. Hansen, F. Guo, R. H. Berg, M. E. Vigild, Macromolecules 2009, 42, 3877.

[21] A. Yamada, B. Sang, M. Konagai, Appli. Surf. Sci. 1997, 112, 216.

[22] K. Grigoras, V. Airaksinen, S. Franssila, J. Nanosci. Nanotechnol. 2009, 9, 3763.

[23] S. Guldin, P. Docampo, M. Stefik, G. Kamita, U. Wiesner, H. J. Snaith, U. Steiner, Small 2012, 8, 432.

[24] S. George, Polymer 2010, 1550, 125.

[25] S. Skoog, M. Bayati, P. Petrochenko, S. Stafslien, J. Daniels, N. Cilz, D. Comstock, J. Elam, R. Narayan, Mater. Sci. Eng. B 2012, 117, 992.

[26] I. Alessandri, M. Zucca, M. Ferroni, E. Bontempi, L. Depero, Crystal GrowthDesign 2009, 9, 1258.

[27] A. Urbas, M. Maldovan, P. DeRege, E. Thomas, Adv. Mater. 2002, 14, 1850.

[28] D. Olson, S. Shaheen, R. Collins, D. Ginley, J. Phys. Chem. C 2007, $111,16670$.

[29] S. Guldin, S. Hüttner, P. Tiwana, M. Orilall, B. Ülgüt, M. Stefik, P. Docampo, M. Kolle, G. Divitini, C. Ducati, S. Redfern, H. Snaith, U. Wiesner, D. Eder, U. Steiner, Energy Environ. Sci. 2011, 4, 225.

[30] J. Boucle, H. Snaith, N. Greenham, J. Phys. Chem. C 2010, 114, 3664.

[31] B. Ehrler, K. P. Musselman, M. L. Böhm, F. S. Morgenstern, Y. Vaynzof, B. J. Walker, J. L. MacManus-Driscoll, N. C. Greenham, ACS Nano 2013, 7, 4210.

[32] Y. Vaynzof, D. Kabra, L. Zhao, P. Ho, A. Wee, R. Friend, Appl. Phys. Lett. 2010, 97, 033309.

[33] F. Li, W. Chen, K. Yuan, Y. Chen, Org. Electron. 2012, 12, 2757.

[34] Y. Sun, J. H. Seo, C. J. Takacs, J. Seifter, A. J. Heeger, Adv. Mater. 2012, 23, 1679.

[35] J. You, L. Dou, K. Yoshimura, T. Kato, K. Ohya, T. Moriaty, K. Emery, C.-C. Chen, J. Gao, G. Li, Y. Yang, Nat. Commun. 2013, 4, 1446.

[36] L. Schmidt-Mende, J. L. MacMagnus-Driscoll, Mater. Today 2007, $10,40$.

[37] A. Buffet, A. Rothkirch, R. Dohrmann, V. Körstgens, M. M. Abul Kashem, J. Perlich, G. Herzog, M. Schwartzkopf, R. Gehrke, P. Müller-Buschbaum, S. V. Roth, J. Synchrotron Radiat. 2012, 19, 647. 